\title{
Credit Risk in the Australian Banking Sector
}

Brian G ray

This paper presents a brief overview of developments currently taking place in the Australian banking sector relating to the measurement and management of credit risk. Section I provides, as background, a sketch of the structure of banking in A ustralia. Section II considers some of the forces operating within the Australian banking and financial system to increase the significance of credit and capital management in banks. Section III outlines some of the credit risk management practices being adopted in the major A ustralian banks. Section IV looks at the implications of these developments and speculates on the scope for greater use of banks' internal credit risk models, or other possible approaches, for capital adequacy purposes. A summary and brief conclusion are in Section V.

\section{The Structure of Banking} in Australia

The banking system in Australia can be summarised in a number of simple statistics. It comprises forty-three banking groups, with aggregate global assets totaling more than A $\$ 900$ billion. Asset size, including the credit equivalent of all off-balance-sheet activity, ranges from around $A \$ 250$ billion for the largest bank to around $A \$ 300$ million for

$B$ rian $G$ ray is chief manager, $B$ ank Supervision $D$ epartment, R eserve $B$ ank of A ustralia. the smallest. As a group, banks hold more than 75 percent of the assets held by all financial intermediaries in A ustralia. The four major banking groups account for more than 75 percent of that total. M easured in terms of the assets of the financial system as a whole (including insurance companies and fund managers), banks now account for just less than 50 percent.

The history of banking in Australia can be summarised as one in which a long period of heavy regulation was followed by a period (dating from the late 1970s to the early 1980s) of financial deregulation. Banks dominated the system in absolute terms for many years but lost ground over the years to the newly emerging (and largely unregulated) nonbank sector. Between the late 1920s and 1980, banks' share of intermediated assets fell from around 90 percent to about 55 percent. That trend changed with the advent of financial deregulation. Thelong-term slide in the proportion of financial assets held by the banks was halted, and the expansion in the number of domestic and foreign banks operating in the Australian market, combined with the additional freedoms given to banks as a result of deregulation, enabled banks' share of business to rise. These trends have been widely documented and will not be examined in this paper.

In contrast to the position in a number of countries, banking in Australia encompasses all aspects of 
financial intermediation. Banks are the main providers of funds to households (through personal lending and lending for residential housing) as well as to the small and medium-sized business sectors. They are involved heavily in wholesale and institutional markets, including all aspects of traded markets. Through fully owned subsidiaries, they are prominent in insurance and funds management. There are no limitations or artificial barriers of substance to the type of activity that can be conducted through a bank or its associated companies, provided the activity can be classified as financial in nature.

\section{Risk Management AND the UndeRLYING FORCESIN AUSTRALIAN BANKING}

Three sets of forces have been instrumental in generating greater interest over the past five years in risk measurement and management within the A ustralian banking system:

- the after-effects of the 1988 and 1992 periods, which saw some A ustral ian banks suffer large losses (Chart 1). This experience led to a recognition that in a world characterised by financial deregulation, the potential existed for large volatility in earnings (and potentially large losses) induced by credit cycles. The product was a new-found interest on the part of bank management in ways to measure and manage credit and other forms of risk more precisely so as to avoid, as far as possible, the reemergence of such problems in the future.

- a recognition that the increasing volume and complexity of financial instruments and products required that better ways be found to measure associated risks. Growth and increasing complexity were not limited to traded financial products, but also extended to many balance-sheet products offered to the household and business sectors that involved complex structures, often incorporating hard-to-measure degrees of optionality.

- the structural changes taking place in the financial sector and the growth in competitive pressures. D espite the post-deregulation resurgence in the growth of "banking" as opposed to "nonbank" activities, the middle years of the 1990s and beyond have been a period of increasingly strong competition in the financial system, and that trend is likely to continue. Against a background of falling underlying profitability, banks have begun to place greater focus than ever before on the maintenance of shareholder returns and the potential for improved risk measurement and management practices to enhance performance through better portfolio selection and management.

This is the broad canvas against which the issue of possible regulatory-induced inefficiencies has emerged in the Australian market. Central to the Australian regulatory system is the 1988 Capital Accord, which (among other things) provided a rough rule-of-thumb for the measurement of required regulatory capital. The capital adequacy arrangements were readily accepted within the Australian banking system and, for a long time (often to the frustration of bank supervisors), were even used as an internal mechanism for allocating capital within at least some banks. This was possible, in large part, because banks' capital levels were well in excess of the regulatory minimum; in reality, capital allocation (to the extent that it was practiced at all) was very much a mechanical process with little meaning to the actual business activities of banks (Chart 2).

That situation is now in the process of changing and the gap between the current capital adequacy arrange ments and the work being carried out by banks in relation to credit risk is becoming more apparent. Analogies are being drawn between the innovative regulatory approach adopted for traded market risk and the existing credit standards. At this stage, the arguments being presented by the main Australian banks are still in the early stages of development, and it could not be said that there is a strong consensus for change, at present, to the existing arrangements.

\section{Chart 1}

Banks' O perating Profit Att ribut able to Shareholders Ratio to A verage Shareholders' Funds

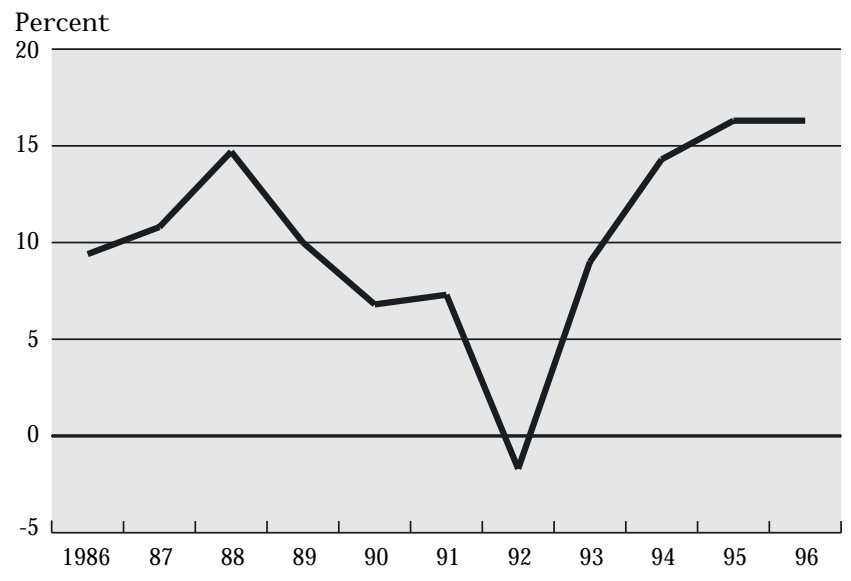


Chart 2

Aggregate Capit al Ratio

Australian Banking System

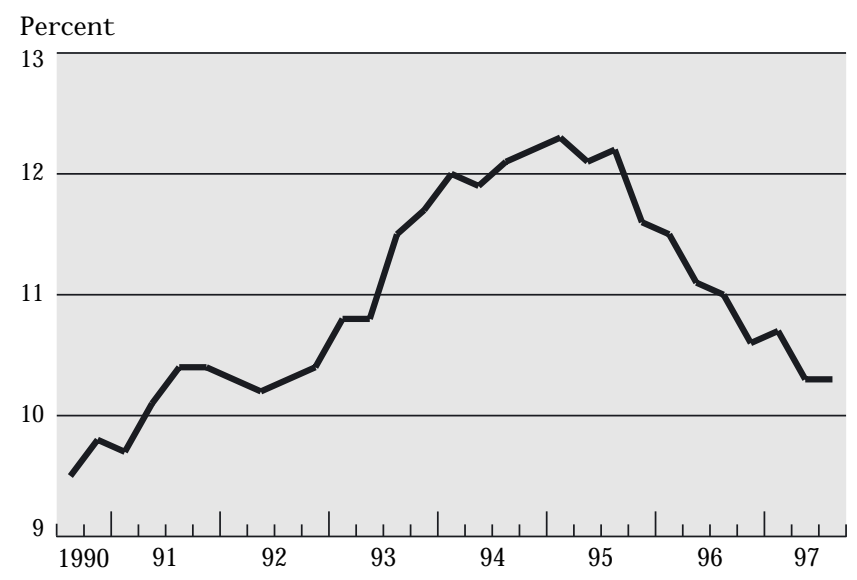

H owever, it is only a matter of time before calls for change become more pronounced. N ow would seem to be the right time, therefore, to think seriously about how an al ternative approach to the treatment of regulatory capital might be developed.

\section{Credit Risk Management} IN AUSTRALIAN BANKS

W hat is the current state of play concerning credit risk management in the A ustralian banking system? W hile it is difficult in a short paper to outline the full scope of activities taking place, and the pace of evolution, this section attempts to give an impressionistic feeling for the nature of changes we are seeing.

First, some general observations. As discussed above, there is no doubt that up until the early 1990s, credit risk measurement was at a rudimentary level in Australian banks, while the management of credit risk was largely subjective. It was a system that relied on experienced and skilled credit officers within the banks. Little attention was paid to assessing, in an objective manner, the nature and extent of credit exposures. In some cases, formal credit systems (in the modern sense of the term) were virtually nonexistent.

Since then, Australian banks have greatly improved their credit measurement capabilities as well as the broader systems in place to track and report on credit exposures. This is possibly the key finding of the program of credit risk visits initiated by the Reserve Bank of A ustralia in 1992. Credit processes are now better documented and understood within institutions. Asset and security valuation arrangements, a particular problem during the last credit cycle, are much tighter than in the past. There is a new focus on the accuracy and timeliness of information on counterparties. There is now widespread use within banks of risk grading systems, and credit approval and monitoring processes are being automated. There is now greater separation between the credit and marketing functions within banks. In some places, centralised credit bureaus have been developed to draw together information on, and take responsibility for, credit risk management at the group level. A more recent trend has been the emergence of centralised and independent risk management groups that seek to assess, in an integrated fashion, all risks faced by a banking group (such as credit, market, operational, and legal). The output of such groups is routinely circulated to senior management within banks and bank boards.

The criteria necessary to assess the effectiveness of risk management systems are, of course, multifaceted, touching on such issues as the quantity and quality of underlying data collected on customers and their exposures, through to the extent to which formal risk grading is used, how it is used, the degree to which pricing of exposures is linked to the grading system, whether risk-adjusted returns are measured and used within an institution, and the extent to which broader portfolio modeling is adopted to take into account correlations between counterparty and/or industry exposures. Once again, the general conclusion is that techniques are evolving rapidly, though the rigour of the methodologies used and the comprehensiveness of credit risk management processes vary among banks. There is no doubt that in relation to some of the more complex or leading-edge aspects of credit risk measurement and portfolio management, "thinking" on what is required is still well ahead of actual application or implementation.

Some of the criteria by which credit risk manage ment systems might be judged, described above, are considered in greater detail below. For the purposes of discussion, the focus will be mainly on the larger Australian banks. 


\section{Data Collection}

Banks now store a wide range of information on counterparties, from the value of all exposures measured across the whole banking group and against limits, to a wealth of financial and other information on the counterparty, including a history of share prices, where applicable. Typically, data required to conduct extensive cash flow analysis on borrowing firms as well as on associated industry prospects are now coll lected or cal culated. W hile there has been significant progress in risk-based data collection by Australian banks, in many cases the data sets still cover only rel atively short time frames. This reflects the fact that many banks did not collect extensive risk-related information, or did not store such information in a useful form, prior to the upsurge of work in this area over the past few years. A ccess to good qual ity, risk-related data remains an important constraint to the wider application of credit analysis and modeling within the Australian system.

\section{RISK GRADING}

Risk grading is now carried out by the bulk of Australian banks. Though subjective assessment is still used by banks (as it should be), energy has been devoted to the application of statistical techniques to introduce greater objectivity into the grading process and to provide benchmarks against which subjective assessments can be gauged. Credit applica tion and behavioural scoring are now commonplace where retail/consumer portfolios are concerned, with tailored models used for the measurement of risk in the corporate and institutional banking areas. Grading systems naturally tend to vary between banks, with the number of grades and demarcations between grades reflecting the structure of banks' balance sheets. W here possible, gradings are benchmarked, in the absence of comparable Australian data, against U.S. default and loss data compiled by Moody's and Standard and Poor's or assessed against K MV or like methodologies. Some banks have adopted external models to assist in the risk grading and portfolio management process. In others, the output of grading systems is carried through to an assessment of the required level of general provisions (a process termed "dynamic provisioning") and then through to profit and loss.
RISK GRAdING AN D PRICING

A logical extension of risk grading is the determination of risk-adjusted pricing for exposures. At this stage at least, it is not clear that this process has gone far within the Australian banking system. Some banks have certainly used their estimates of risk to decline exposures that do not meet their risk/return requirements, and there has been a definite move away from the simple "pass/fail" mentality of the past to one more sympathetic to the view that riskiness is a continuum that should be reflected in pricing. $\mathrm{H}$ owever, a common theme of risk managers in Australian banks is the difficulty in introducing more active pricing for risk regimes within their banks; the difficulty being "selling" the idea that an otherwise good exposure should not be accepted because a "technical" assessment shows that there is an imbalance between risk and expected return. It is an especially difficult message to convey to senior bank management when competitive pressures in the market are strong. This raises the broader issue of the "cultural" changes needed within a bank to make risk management (broadly defined) truly effective, and the need for an extensive "top down" education process within financial institutions. This issue is touched upon further below.

Measurement of Risk -Adjusted Performance The leading Australian banks have begun to measure risk-adjusted performance and estimate "economic" measures of capital. The accuracy of these measures will, of course, turn on how well the underlying data and the related grading systems capture risk. The absence of comprehensive data on how well or otherwise the Australian banking sector performs in times of economic downturn will, for some time, place a question mark on the reliance that can be put on such figures, especially those relating to business and corporate loan exposures. $\mathrm{N}$ onetheless, the estimates are being produced routinely by the leading banks and circulated to the highest levels within the banks. In some banks, remuneration policies are now being geared off of risk-adjusted performance measures. 


\section{USE OF Broader Portfolio Models}

$W$ hile it is acknowledged that there are benefits to be gained in adopting active portfolio diversification techniques, the leading Australian banks are still very much at the experimental stage in examining the potential offered by such approaches. Allen (1997) has summarised the state of play in relation to portfolio diversification techniques and their applicability to Australian banks. $\mathrm{H}$ is analysis and conclusions are not repeated here. Suffice to say that it is likely to be some time before the potential advantages offered by portfolio-based approaches are implemented within the institutions. Short of full acceptance of such techniques, however, banks have begun to experiment with buying and selling loans to realise better balanced portfol ios while credit derivatives are being used more actively to the same effect (though the market in Australia is still quite small). Securitisation of banks' more homogeneous portfolios has been a feature of the Australian banking scene for several years, though there have been only limited attempts to date to securitise other, less uniform credit portfolios.

To summarise, the past five years have witnessed a rapid evolution in approaches to credit risk in the Australian banking system. W hether "world best practice" can realistically be applied to present credit risk measurement and management practices in all the leading Australian banks is questionable, though it is equally questionable just how many international banks with bal ance sheets comparable to Australian banks would justify that description.

A useful trend observed in this market is the recognition (referred to above) that improving risk management within banks is as much about changing attitudes to risk as it is about introducing complex technical models to the organisation. It is important to avoid the temptation to view the issue of improved risk management as essentially technical in nature. N immo (1997) recently referred to the challenges of improving risk management within a major bank in the following terms:

Improved risk management, therefore, requires significant cultural change to make it effective. Implementation creates a great deal of discomfort amongst bank staff because it requires people to move away from traditional ways of doing things, to ways that are more logical but nonetheless unfa miliar. There is typically huge resistance to that process of change. $\mathrm{N}$ evertheless, these changes have to be implemented in such a way that they form a fundamental part of the management of financial institutions.... The question is whether the commitment exists within institutions to actually make the changes which, in time, will deliver the shareholder val ue that waits to be extracted.

\section{IMPLICATION S FOR SUPERVISORS}

Risk management practices have improved in the Australian banking system and the range of techniques now being applied is expanding and growing in complexity. To what extent does this suggest the need for supervisors to reassess their current approach to the measurement of regulatory capital?

It could be argued that while such developments are highly desirable in their own right, they have little implication for supervisors whose role is to set minimum supervisory and capital standards. Existing capital adequacy arrangements could be seen as satisfying this role- maintaining the pressure on minimum capital levels and generally ensuring better coordination of capital rules internationally (one of the original aims). Provided that the arrangements are not used by banks to influence lending or portfolio decisions (which should always be the product of more sophisticated methodologies than those imposed by supervisors), then the implications of retaining the existing arrangements should not be too significant.

There are a number of counterarguments, but the key one relates to the issues of supervisory relevance and financial market efficiency. W hile there is little reason for bank supervisors to lead the market in the application of new risk technologies for supervisory purposes (a strong case can be made against taking that approach), there are al so problems in their falling behind market developments. Effective supervision hinges, in large part, on supervisors maintaining credibility and being able to demonstrate that their policies have relevance to the world in which they apply. That was the case in 1988, when the capital adequacy arrangements were first introduced, and it can also be said 
of the recent amendment to the Capital Accord covering market risk. If the banking industry is developing better methods for the measurement and management of risk, and genuinely using those techniques in their risk management activities, then it is reasonable to expect that supervisors will assess those developments against existing arrangements.

Competitive pressures in banking also need to be borne in mind. There has been an increasing tendency in the Australian market for nontraditional providers of finance to enter and compete strongly in areas formerly occupied mainly by banks. That trend, which is likely to become stronger over time, should be encouraged in the interests of greater competition. In many cases, however, these new providers are not supervised as intermediaries, nor should they be given the particular structures under which some of them operate (through securitisation vehicles and so on). O ne effect of the new competition in banking, therefore, may be to increase the competitive disadvantages associated with current forms of regulation, a point al ready made strongly by some banks. Market efficiency considerations, therefore, come into the equation and further strengthen the case to look at al ternative regulatory options.

\section{IN TERN AL M ODELS}

The obvious option to consider is the use of internal credit models for regulatory purposes. The issue is more complex, however, than simply observing the increased use of such models in the market and concluding that they should be applied for supervisory purposes. Even if such an approach was accepted as a good idea in principle, the real question is how the arrangement could be made workable, be efficient from a market perspective, and satisfy prudential objectives. There are some significant obstacles.

The fact that credit risk is the biggest risk factor confronting most banks is a major issue and possibly a key obstacle to the adoption of internal models. W hile market risk has the potential to cause serious damage to some banks, it is relatively insignificant for the bulk of A ustralian banks. The risk of experimenting with alternative methodologies, therefore, is much less critical where market risk, as opposed to credit risk, is concerned.
As discussed above, the practical matter of data will al ways be a critical problem where credit risk modeling is concerned. In Australia's case, for example, there is no long-term history of default and loss rates across different categories or grades of counterparty; that observation would hold true for many other countries as well. The data that are available (mainly from the U nited States) show a wide variation in risk across different gradings. For the lower grades, risks also appear highly cyclical, skewed, and "fat tailed." This means that the determination or interpre tation of average and worst-case loss, or volatility of loss, is much more complex for credit risk than for traded market risk, where price and volatility data, and hence estimates of losses or gains, can be estimated continuously. Yet getting the numbers right in relation to credit risk is critical. M igration from one credit grading to another lower grading can often involve exponential increases in default risk. Capital adequacy arrangements built on inadequate or incomplete data may, therefore, generate dangerously inadequate results. The skeptic might conclude, on that basis al one, that internal models offer little, but carry very significant risks.

Yet as we look at the current arrangements, it is hard to believe that they could be the appropriate regula tory model to take the rapidly evolving banking system into the next century. The simplicity of the present framework, which at the beginning was one of its great virtues, will, in a more complex financial system, become its greatest failing. The financial world has become more complex and the regulatory world must move in step. The issue, there fore, is not whether regulatory arrangements should be modernised, but rather how they can be achieved in a bal anced way, in a reasonable time frame.

As the world of internal models is approached, it will almost certainly be argued that problems of consistency will arise- how to ensure equal treatment across different institutions. It should be recognised, however, that simple approaches already suffer severely from this problem. To use an admittedly overly used example, the current system can generate the same capital requirement for a bank holding only blue-chip corporate exposures as it can for another bank holding loans to risky small 
businesses. That approach cannot be generating the right messages either for the bank, the supervisor, or the market. The true capital needs of an institution can be determined only from the risk characteristics of its balance sheet and its other exposures. That must be true not only for internal management purposes but also for the purposes of regulation.

\section{W ill Capital Levels Fall?}

A common concern is that the use of credit risk models will lead to lower overall capital levels in banks. That need not occur. U nder the market risk guidelines, for example, the output of the banks' models is multiplied by a factor to produce the required degree of conservatism for regulatory purposes. That approach, or some variant of it, could be adopted in any future approach applied to credit models. Alternatively, the use of capital estimates derived from internal models, combined with a capital floor determined by some simpler regulatory-based methodology, could also be considered.

It is worth noting, in this context, that tentative estimates of possible capital requirements flowing from the use of credit models have been made by a number of A ustralian banks. U sing some quite conservative assumptions, the results point to credit risk capital requirements of around half of those required under the existing arrangements. However, when estimates of possible operational risks are taken into account (A ustralian banks are also attempting to quantify this component of risk as part of the risk mapping exercises being carried out within the institutions), then the resulting overall capital figure increases again to something not greatly different from the present requirement. This might suggest the need for any new capital adequacy arrangement to reach more broadly than just credit risk, perhaps into the area of operational risk. Possibly the time has come to develop an even broader approach encapsulating all forms of measurable risk. Although this would add greatly to the complexity of the regulatory development task, it would be consistent with the trend observed in banks to look in an integrated way at the broad range of risks being faced as a result of their activities.

\section{OTHER POSSIBILITIES}

To the extent that the simplicity of the present capital structure is seen as desirable, there may be merit in contemplating an extension to the risk grading system built into the current arrangements. It is possible to envisage the risk weighting scale extended from the current five grades to a higher number (say, ten), thereby providing greater demarcation between gradings. M ovement in this direction has al ready occurred to some extent through the introduction of concessional risk weightings under the market risk (standard method) guidelines. This might deliver a closer alignment of regulatory capital rules with more "economic-based" measures of risk. W hile possible, this approach would not align with broader portfolio modeling approaches where the impact of a single counterparty on a bank's overall credit risk might differ depending on the structure of the portfolio itself. Such portfolio-based approaches would raise challenges for any supervisory system that continued to measure credit risk on the basis of fixed risk gradings. Perhaps more importantly, to the extent that internal models are viewed as the appropriate long-term approach to capital adequacy, it may be best to avoid "band-aid" solutions that could divert attention from the ultimate goal. The simplified approach may have some relevance, however, for the less sophisticated of the banks and those with simpler balance sheets. W hatever new arrangements were introduced, there would still be a need for a simpler al ternative for the less advanced banks.

There may also be merit in exploring, for application in the area of credit risk, some of the ideas developed over recent years by $\mathrm{K}$ upiec and $\mathrm{O}^{\prime} \mathrm{B}$ rien in relation to "precommitment." The precommitment proposal is targeted at the calculation of a capital charge for traded market risk. A bank commits to a maximum loss over a fixed period and allocates capital to cover the exposure. The bank is given incentives to set realistic, and sufficiently conservative, capital charges- incentives that take the form of penalties if a bank's losses exceed its committed capital. It would avoid the need for supervisors to preordain a fixed methodology for measuring risk - with the appropriateness of any bank estimates of risk and loss determined sol ely by results. In theory, this broad approach could be applied to any form of risk. 
It is not at all clear how this approach could translate to the area of credit risk (the authors see its application largely to the area of market risk). W hereas a bank could be assessed on a precommitment model designed to cover market risk at regular intervals (quarterly, for example), that would not be possible where credit risk is involved since the nature of credit cycles is such that true tests come only infrequently (that is, over a full economic or banking cycle). W hen problems do arise, they have the potential to be serious events. There would have to be serious doubts about the credibility of any approach that is based on the application of sanctions where losses involved might be very significant or even institution-threatening.

$\mathrm{N}$ evertheless, the idea of a system based on the concept of banks committing to a certain level of capital, with supervisors avoiding the need to attempt a complex standardisation of rules and parameters surrounding credit models, is an attractive thought and worth exploring.

\section{DisCLOSURE-BASED APPROACHES}

Much of the discussion above assumes the ongoing presence of a capital-based regulatory regime. Another quite different and more radical approach is also worthy of mention. It would involve stepping away completely from any formal determination of capital requirements and insisting upon much greater disclosure by banks, allowing the market to determine the relative degrees of safety attached to the different institutions. This thought process lies behind the current regulatory regime in $\mathrm{N}$ ew Zeal and (though it should be noted that the supervisory authority in that country has, in fact, retained much of the traditional supervisory and capital adequacy structure).

In a disclosure-based approach, banks would be required to provide detailed information on their measurements of credit risk, the methodologies used to derive the estimates, capital holdings, and any other data or information relevant to interested parties. To the extent that a bank stepped out of line with established banking norms, these external parties would go elsewhere or demand changes within the institution, the result being that the institution would either go broke or be forced to comply with market expectations, whether they be in relation to capital, risk levels, liquidity arrangements, management structure, or something el se.

There is a very strong case to be made favouring greater market discipline on the banking sector, and supervisors, internationally, have been at the forefront of the debate on disclosure. The issue, however, is not about the merits of improved banking disclosure as such (about which there is little debate), but the extent to which disclosure could form a realistic alternative to the more traditional capital-based approach.

Ultimately, it is a philosophical judgment as to whether market-based approaches might work or whether the health and safety of the banking sector are considered too important to leave entirely to the market. The latter is the mainstream view and one that is likely to be maintained. Acceptance of this position in no way reduces the importance of improved disclosure of financial information by institutions.

\section{Assessment AN D CON CLUSIONS}

There is no definitive answer to the question of how capital adequacy arrangements, or indeed supervisory arrange ments more broadly defined, should evolve in the future. The emphasis on risk-based capital adequacy as the basis for supervision in the industrialised world is now firmly established and seems unlikely to change in the foreseeable future.

The option of leaving the current arrangement in place in its present form (or with some minor modifications) may be realistic as far as most banks are concerned. However, the activities of the leading banks are pushing regulatory arrangements in the direction of greater sophistication of credit risk measurement (just as they did in the case of market risk measurement). Credit modeling is still in an early phase of development in the Australian market and it would be unreal istic to believe that a regime based on that approach is viable in the short term. H owever, developments are occurring quickly and credit modeling will become much more significant for banks in the medium term. Very importantly, growing competition in the provision of financial services may be increasing the competitive disadvantages associated with existing arrangements. 
As supervisors of the A ustralian banking system, we are keen to see the supervisory structure evolve with the market. W ithout trying to downplay the complexities that will be involved, we believe there is a strong case to commit to the development of an approach to capital adequacy that utilises better measures of credit risk and portfolio modeling techniques. Over the longer term, more integrated approaches to risk measurement (for example, embodying credit, market, and operational risk) may need to be the goal. Looking specifically at credit risk modeling, there is reason to bel ieve that a relatively large number of Australian banks would in time see themselves as potential model users. The work currently being done by the major banks in Australia provides grounds for a belief that internally based models could be a feasible option for that group. Even for the smaller regional banks, with a high proportion of residential housing on their balance sheets, it would be a relatively simple task to model credit risk, given the stability of residential housing default and loss rates in A ustral ia over a long period (this is one of the few reliable long-term statistics available in this market).

How soon might all this occur? Realistically, it may be some years before credit risk modeling becomes feasible in the Australian system, and longer than that for more sophisticated approaches that attempt to integrate different forms of risk within a single framework. However, developments are occurring rapidly in the banking system and it is al so the case that supervisory arrangements have evolved in recent years and supervisors (as a group) are now technically better equipped to deal with complex issues, such as credit modeling, than they were a decade ago. Together, these factors may bring the respective time frames forward.

The views expressed in this article are those of the author and do not necessarily reflect the position of the Federal Reserve Bank of New York or the Federal Reserve System. The Federal Reserve Bank of New York provides no warranty, express or implied, as to the accuracy, timeliness, completeness, merchantability, or fitness for any particular purpose of any information contained in documents produced and provided by the Federal Reserve Bank of New York in any form or manner whatsoever. 


\section{REFERENCES}

Allen, W. 1997. "Alternative Approaches to the Diversification of Portfolios." In B. Gray and C. Cassidy, eds., CREDIT RISK IN BAN KIN G, 166-88. Sydney: Reserve Bank of Australia.

Conroy, F. 1997. "M anaging Credit Risk-An Overview: Discussion." In B. Gray and C. Cassidy, eds., CREDIT RISK IN BANKING, 21-3. Sydney: R eserve Bank of Austral ia.

Edey, M., and B . G ray. 1996. "The Evolving Structure of the A ustralian Financial System." In M. Edey, ed., The Future OF THE Fin An CIAL SY STEM, 6-44. Sydney: Reserve Bank of A ustralia.

G renville, S. 1991. "The Evolution of Financial Deregulation." In I. Macfarlane, ed., THE DEREgULATION OF FINANCIAL INTERMEDIARIES, 3-35. Sydney: Reserve Bank of Australia.

Kupiec, P. H., and J. M. O'B rien. 1995. "A Pre-Commitment Approach to Capital Requirements for Market Risk." Board of Governors of the Federal Reserve System Finance and Economics Discussion Series, no. 95-36.
N immo, R. 1997. "R ound Table Discussion." In B. Gray and C. Cassidy, eds., CREDIT RISK IN BANKING, 254-6. Sydney: ReserveBank of Australia.

Smout, C . 1997. "The Bank of England: W hat's on the Agenda?" Paper presented at IBC Conference "Responding to and Preparing for the Implementation of Basle/CAD 2 and the Changing Regulatory Framework," London, A pril 8-9.

Thompson, G. J. 1991. "Prudential Lessons." In I. Macfarlane, ed., THE DeREgulation of Financial InTERmediaries, 115-42. Sydney: Reserve Bank of Australia.

W allis, S. 1997. "Financial System Inquiry Final Report," March. 